\title{
Cancer patients' wish for psychological support during outpatient radiation therapy
}

\section{Findings from a psychooncological monitoring program in clinical routine}

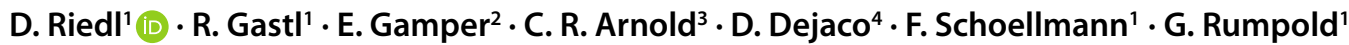

Received: 28 October 2017 / Accepted: 20 February 2018 / Published online: 12 March 2018

(c) The Author(s) 2018. This article is an open access publication.

\begin{abstract}
Background Cancer patients frequently suffer from physical and psychosocial impairments due to their disease and its treatment. Psychooncology (PO) can help to cope with stress resulting from outpatient radiotherapy (RT) treatment. There are currently few data regarding patients' wishes for PO support. The aim of this study was to investigate the number of patients with a wish for PO, treatment paths, and predictors of the wish for $\mathrm{PO}$ among cancer patients at the beginning of RT.

Methods The results of routine psychological stress screening (Hornheide screening instrument; cut-off $\geq 4$ ) of 944 cancer patients between 2015 and 2017 were analyzed in a retrospective cross-sectional study. Predictors for a wish for PO support were identified by stepwise binary logistic regression, in which sociodemographic and treatment data were included in addition to the screening items.

Results Around $20 \%$ of patients had above-average stress levels and $13 \%$ expressed a wish for PO support (participation rate was approximately 55\%). Low emotional wellbeing $(\mathrm{OR}=11.3)$ and lack of social support $(\mathrm{OR}=9.4)$ were strong predictors for this treatment wish. Among patients with pancreatic cancer, head and neck tumors, and hematologic disease, there was a substantial difference between the degree of psychological stress and the wish for treatment. Patients with urological (23.5\%) and lung tumors (20.9\%) most frequently expressed a wish for PO support.

Conclusion Patient-reported psychosocial problems were better predictors of a wish for PO support than sociodemographic or clinical data. Stress screening should thus be implemented in clinical routine.
\end{abstract}

Keywords Psychooncology $\cdot$ Distress screening $\cdot$ Treatment wish $\cdot$ Prevalence $\cdot$ Treatment path

Electronic supplementary material The online version of this article (https://doi.org/10.1007/s00066-018-1288-0) contains supplementary material, which is available to authorized users.

D. Riedl, $\mathrm{PhD}$

david.riedl@tirol-kliniken.at

1 University Clinic of Medical Psychology, Medical University of Innsbruck, Innsbruck, Austria

2 Innsbruck Institute of Patient-reported Outcome Research (IIPCOR), Innsbruck, Austria

3 Department of Therapeutic Radiology and Oncology, Innsbruck Medical University, Innsbruck, Austria

4 Department of Otorhinolaryngology, Medical University of Innsbruck, Innsbruck, Austria 


\section{Der Wunsch der Krebspatienten nach psychoonkologischer Unterstützung während der ambulanten Strahlentherapie}

Ergebnisse eines psychoonkologischen Monitoringprogramms in der klinischen Routine

\section{Zusammenfassung}

Hintergrund Krebspatienten leiden aufgrund der Erkrankung und Behandlung häufig unter körperlichen und psychosozialen Beeinträchtigungen. Psychoonkologie (PO) kann helfen, solche Belastungen im Zuge der ambulanten Strahlentherapie (RT) zu verarbeiten. Gegenwärtig liegen jedoch nur wenige Daten vor, inwieweit sich Patienten eine PO-Behandlung wünschen. Ziel war es, die Anzahl der Patienten mit PO-Behandlungswunsch, Behandlungspfade sowie Prädiktoren des Betreuungswunschs bei Krebspatienten zu Beginn der ambulanten RT zu untersuchen.

Methode Zwischen 2015 und 2017 wurden die Ergebnisse eines routinemäßigen psychischen Belastungsscreenings (Hornheide-Screening-Instrument; Cut-Off $\geq 4$ ) von 944 Krebspatienten in einer retrospektiven Querschnittsanalyse untersucht. Prädiktoren für den PO-Behandlungswunsch wurden mittels schrittweiser binärer logistischer Regression identifiziert. Dabei wurden soziodemographische und behandlungsbezogene Daten sowie Screening-Items einbezogen.

Ergebnisse Etwa $20 \%$ der Patienten zeigten überdurchschnittliche Belastungswerte und $13 \%$ wünschten sich eine PO-Behandlung (Partizipationsrate ca. 55\%). Geringes emotionales Wohlbefinden $(\mathrm{OR}=11,3)$ und fehlende soziale Unterstützung $(\mathrm{OR}=9,4)$ waren starke Prädiktoren für den Behandlungswunsch. Zwischen dem psychischen Belastungsgrad und dem Betreuungswunsch zeigte sich bei Patienten mit Pankreaskrebs, Hals-Kopf-Tumoren sowie hämatoonkologischen Erkrankungen ein substantieller Unterschied. Am häufigsten wünschten sich Patienten mit Krebs in den Harnorganen (23,5\%) und Lungenkrebs $(20,9 \%)$ eine PO-Behandlung.

Schlussfolgerung Patientenberichtete psychosoziale Probleme waren bessere Prädiktoren für den Wunsch nach PO-Behandlung als soziodemographische oder klinische Daten. Belastungsscreenings sollten daher in die klinische Routine implementiert werden.

Schlüsselwörter Psychoonkologie $\cdot$ Belastungsscreening $\cdot$ Behandlungswunsch $\cdot$ Prävalenz $\cdot$ Behandlungspfade

\section{Background}

Despite improved survival rates over the past two decades due to diagnostic and therapeutic advances, cancer remains the second leading cause of death worldwide [1]. A substantial number of cancer patients report short- and longterm psychological distress due to the disease, active treatment, and treatment consequences [2,3]. Between 22\% and $35 \%$ of radiotherapy outpatients report clinically relevant psychological distress [4-7]. High levels of psychological distress warrant clinical attention, since they may negatively influence treatment adherence $[8,9]$, satisfaction with care [10], and health-related quality of life (QoL; [11]). Available data suggest that psychooncological support (PO) can effectively reduce psychological distress and improve patients' QoL [12-14]. However, a large proportion of distressed cancer patients do not receive professional support [14-16]. Multifaceted reasons for this mismatch have been discussed in the literature. Firstly, screening for psychological distress by clinicians is unsatisfactory, resulting in an underestimation of patients' distress levels and a lower number of referrals [4, 17]. Routine distress screening can significantly increase the number of referrals to PO [18]: when actively offered during radiotherapy, $13-41 \%$ of the patients accepted referral $[6,19,20]$. Incorporation of such screening procedures into clinical routine to effec- tively identify distressed cancer patients to enable quick and adequate PO is recommended [21, 22]. Screening is usually conducted with short, easily applicable and interpretable questionnaires, followed up by referral to a more specialized healthcare professional if necessary [23].

Secondly, cancer patients frequently misjudge their own distress levels as not severe enough for PO [24], and restrain from self-referral when in need [25]. This phenomenon was recently described as "normality paradox" by Carolan et al. [26]. Patients aim at maintaining a feeling of normality by rejecting professional support. Additional barriers include lack of local services or financial considerations [27], lack of time or awareness of services, and patient refusal [25]. Higher pain levels, increased support requirement in daily life, increased patient-reported symptoms, and decreased functional status were previously observed as influential factors on self-referral rates to PO. In contrast, clinical characteristics (i.e., tumor entity, presence of metastases) and sociodemographic factors were reported to be nonpredictive [6].

In short, available data suggest that cancer patients significantly benefit from PO, but clinicians and patients themselves restrain from (self-) referral for various reasons. Besides incorporating a more active pattern of referral to available services in clinical practice, factors influencing a patient's decision towards self-referral should be explored 
to identify patients at risk. However, such data collected from large mixed samples during routine assessment, rather than in controlled experimental environments, are rare.

Here, we present data from a routine psychooncological screening procedure during outpatient radiotherapy. In our study, we addressed the following aims: (a) to assess the number of patients who wish for PO across tumor entities, (b) to identify predictors for the wish for PO, and (c) to describe the referral pathways for PO in clinical routine.

\section{Methods}

We retrospectively analyzed data collected in clinical routine from cancer outpatients treated at the Department of Therapeutic Radiology and Oncology (Medical University of Innsbruck) between January 2015 and January 2017.

Patients were included if they were (a) treated for cancer, (b) outpatients, and (c) older than 18 years.

\section{Clinical procedure}

At the Department of Therapeutic Radiology and Oncology, approximately 160-180 patients are treated daily; the vast majority are outpatients. Routine treatment includes the possibility of PO, social work, nutrition counseling, or creative therapy.

The treatment staff (i.e., physicians, radiation therapists, nurses, social workers) offer referral to PO if cancer patients seem distressed. Additionally, all cancer outpatients are asked to complete an eight-item screening questionnaire regarding their need for $\mathrm{PO}$, which is handed out to the cancer patients within the first 3 days of radiotherapy by the staff, and can be returned to the treating physicians or other staff at the radiation units. Participation in the screening procedure is voluntarily and non-participation results in no disadvantage to the cancer patients. The leading psychologist collects the screening tests twice a week, and patients who either had a score above the cut-off and/or wished for PO are contacted soon after.

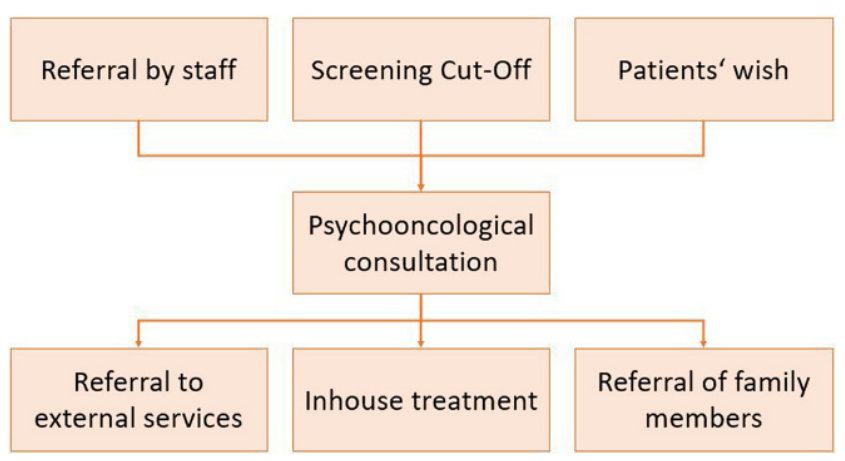

Fig. 1 Treatment flow
Depending on the patients' needs, they receive PO throughout radiotherapy or are referred to external psychosocial services. Referral may include cost-free PO counseling centers close to home, outpatient psychiatrist, specialized psychotherapists, or counseling by social workers. Furthermore, support is offered to distressed family members. This often comprises providing information or referring to external services (see Fig. 1).

\section{Screening questionnaire and data collection}

To assess the need for PO, the Hornheide Screening Instrument (HSI) was used. The HSI consists of seven items assessing physical and emotional well-being, additional emotional burden unrelated to disease, social support, burden on family through hospital stay, the inability to calm down, and the level of information about disease and treatment. The items can be added up to a total score (range $0-14)$. Values $\geq 4$ indicate the need for PO.

We added one further dichotomous item asking patients if they wish for PO.

\section{Statistical analysis}

Descriptive statistics were calculated to describe the sample, prevalence of the wish for PO, and referral pathways for PO. To identify factors that predicted the wish for PO as indicated by the dichotomous variable, we conducted a stepwise binary logistic regression. In a first step, we tested the association of sociodemographic and clinical variables (cancer sites, previous treatments, histological grading, disease state, and treatment concept) and in a second step the association of the seven HSI items. Significant predictors of each block were selected using the backward elimination method (likelihood ratio test) and were entered in the final model. Educational levels were dichotomized into low (below higher school certificate) and high (at least higher school certificate) education. We included the three most frequent tumor locations (breast, prostate, and lung) as categorical variables and consolidated the remaining tumor locations into a single group. Odds ratios (OR) are presented with $95 \%$ confidence intervals (CI).

\section{Results}

Between January 2015 and January 2017, approximately 1700 cancer outpatients were treated at the Department of Therapeutic Radiology and Oncology. A total number of 961 cancer patients returned the screening instrument, leading to a participation rate of approximately $55 \%$. Of these, 17 cancer patients $(1.8 \%)$ were excluded since they did not meet the inclusion criteria. Five cancer patients 
Table 1 Clinical data

\begin{tabular}{|c|c|c|}
\hline & $n$ & $\%$ \\
\hline \multicolumn{3}{|l|}{ Cancer sites $^{\mathrm{a}}$} \\
\hline Breast cancer $(\mathrm{C} 50)$ & 320 & 33.9 \\
\hline Prostate cancer (C60-63) & 209 & 22.1 \\
\hline Lung cancer (C33-34) & 116 & 12.3 \\
\hline Head and neck cancer (C00-14; C30-33) & 49 & 5.2 \\
\hline Colorectal cancer $(\mathrm{C} 18-21)$ & 49 & 5.2 \\
\hline Brain cancer $(\mathrm{C} 70-72)$ & 40 & 4.2 \\
\hline Hemato-oncological cancer (C81-96) & 40 & 4.2 \\
\hline Malignancy of connective and soft tissue & 21 & 2.2 \\
\hline Gynecological tumors (C51-58) & 19 & 2.0 \\
\hline Melanoma (C43-44) & 19 & 2.0 \\
\hline Urinary organs (C64-68) & 16 & 1.7 \\
\hline Secondary and ill-defined (C76-80) & 15 & 1.6 \\
\hline Gastric cancer (C15-17) & 11 & 1.2 \\
\hline $\begin{array}{l}\text { Pancreatic cancer (incl. liver and gall bladder: } \\
\text { C22-25) }\end{array}$ & 10 & 1.1 \\
\hline Other & 10 & 1.1 \\
\hline \multicolumn{3}{|l|}{ Previous treatments } \\
\hline Radiotherapy & 75 & 7.9 \\
\hline Surgery & 422 & 44.6 \\
\hline Chemotherapy & 143 & 15.1 \\
\hline Hormonal therapy & 232 & 24.5 \\
\hline Immunotherapy & 27 & 2.9 \\
\hline \multicolumn{3}{|l|}{ Histological grading } \\
\hline Grade I & 58 & 6.1 \\
\hline Grade II & 422 & 44.7 \\
\hline Grade III & 226 & 23.9 \\
\hline Grade IV & 36 & 3.8 \\
\hline Missing values & 202 & 21.4 \\
\hline \multicolumn{3}{|l|}{ Treatment concept } \\
\hline Curative & 748 & 79.2 \\
\hline Palliative $^{\mathrm{b}}$ & 196 & 20.8 \\
\hline
\end{tabular}

aCD-10 codes

bPalliative treatment medical treatment of incurable diseases aiming primarily at symptom control and improvement of quality of life

did not complete the screening questionnaire, but stated their wish for PO and were therefore kept in the analyses. For the finally included 944 cancer patients, mean age was 63.9 years, $50.6 \%$ were female, $68.9 \%$ were married or in a long-term relationship, and $85.0 \%$ had children. About half of the cancer patients had finished compulsory school and an apprenticeship (55.5\%), and almost a third (30.0\%) had higher education or a university degree.

The most frequent tumor locations in the cohort were breast, prostate, and lung cancer. The proportion of patients with breast cancer was comparable to the total population of outpatients treated at the department $(33.9 \%$ vs. $31.4 \%)$, while patients with prostate cancer were slightly overrepresented $(22.1 \%$ vs. $18.8 \%)$ and patients with lung cancer slightly underrepresented (12.3\% vs. $14.9 \%)$.
Most cancer patients (73.0\%) were treated for a primary disease and with a curative treatment plan. Within the three most frequent tumor locations, patients with breast cancer and prostate cancer were mostly treated with a curative treatment plan $(91.9 \%$ and $89.4 \%$, respectively), while palliative treatment was more frequent in patients with lung cancer $(47.8 \%)$. The majority of the cancer patients (89.6\%) had a Karnofsky Performance Score between 80 and 100. For details on clinical data, see Table 1.

\section{Prevalence of the wish for psychooncological support}

Most cancer patients ( $>90 \%)$ reported medium or good physical and emotional well-being and having someone to talk to about concerns and fears. Yet, about $17.2 \%$ reported that their illness affected family members and that they were currently troubled by other topics. The vast majority of cancer patients felt well informed about their disease and treatment.

In total, 185 cancer patients $(19.7 \%)$ were identified as potentially in need of PO (HSI score $\geq 4$ ), and $42.7 \%$ of these wished for PO. Another $5.7 \%$ of the cancer patients below the cut-off also wished for PO, resulting in a total of $13.1 \%$ of all included cancer patients. Some of these cancer patients already received PO and were therefore not contacted by a psychooncologists. Healthcare professionals referred 14 cancer patients with negative screening results who had not stated a wish for PO and another 85 cancer patients who had not returned their questionnaire. This resulted in 204 cancer outpatients who received PO during their radiotherapy. Of these patients, $39.7 \%$ received one consultation, $41.2 \%$ received $2-3$ consultations, and the remaining $19.2 \%$ received $4-9$ consultations. For details see Fig. 2.

A large proportion $(40.7 \%)$ of the cancer patients who were consulted only once were referred to other healthcare services, mostly to cost-free PO counseling centers close to home (33.3\%), to outpatient psychiatrists (30.3\%), or to psychotherapists $(21.2 \%)$. Another $12.1 \%$ of these cancer patients were referred to the inhouse social worker for social counseling; $6.4 \%$ aborted the PO. Cancer patients who had not taken part in the screening procedure were referred to external services significantly more often than patients with available screening data $(63.6 \%$ vs. $36.4 \%$; $\mathrm{Chi}^{2}=6.2, p=0.013$ ).

The number of cancer patients above the cut-off strongly varied amongst cancer types, showing the highest percentage amongst patients with gynecological cancer, cancer in the urinary organs, and hemato-oncological malignancies. The lowest proportion of distressed patients was found in gastric cancer and prostate cancer. As shown in Fig. 3, there was some variation between the percentage of patients 
Fig. 2 Description of the referral pathways for patients with (left side) and without screening (right side). $P O$ psychooncological support, $H C P$ health-care professional
Fig. 3 Percentage of patients above the HSI cut-off and percentage of patients who wish for psychooncological support

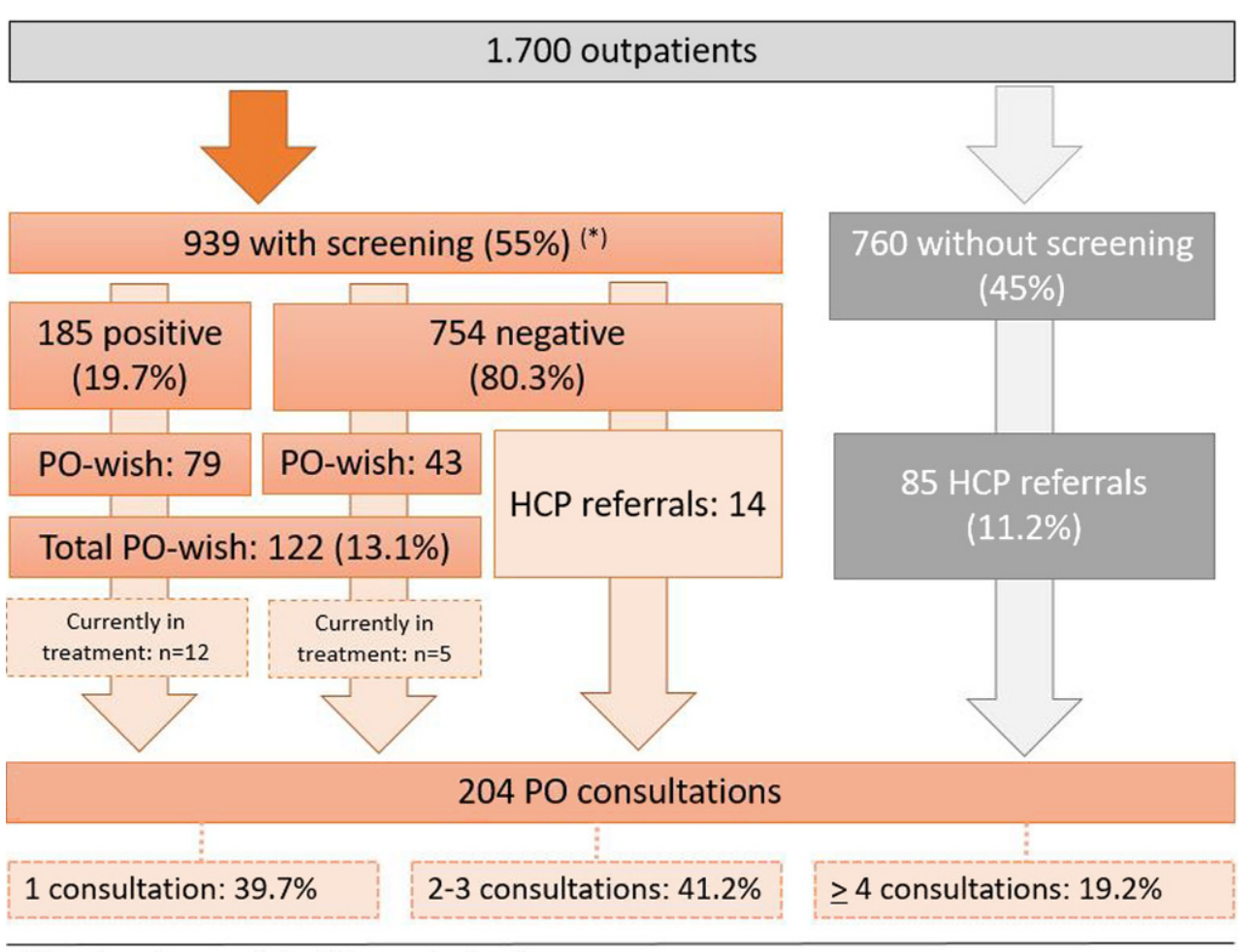

(*) $n=5$ patients excluded due to missing data

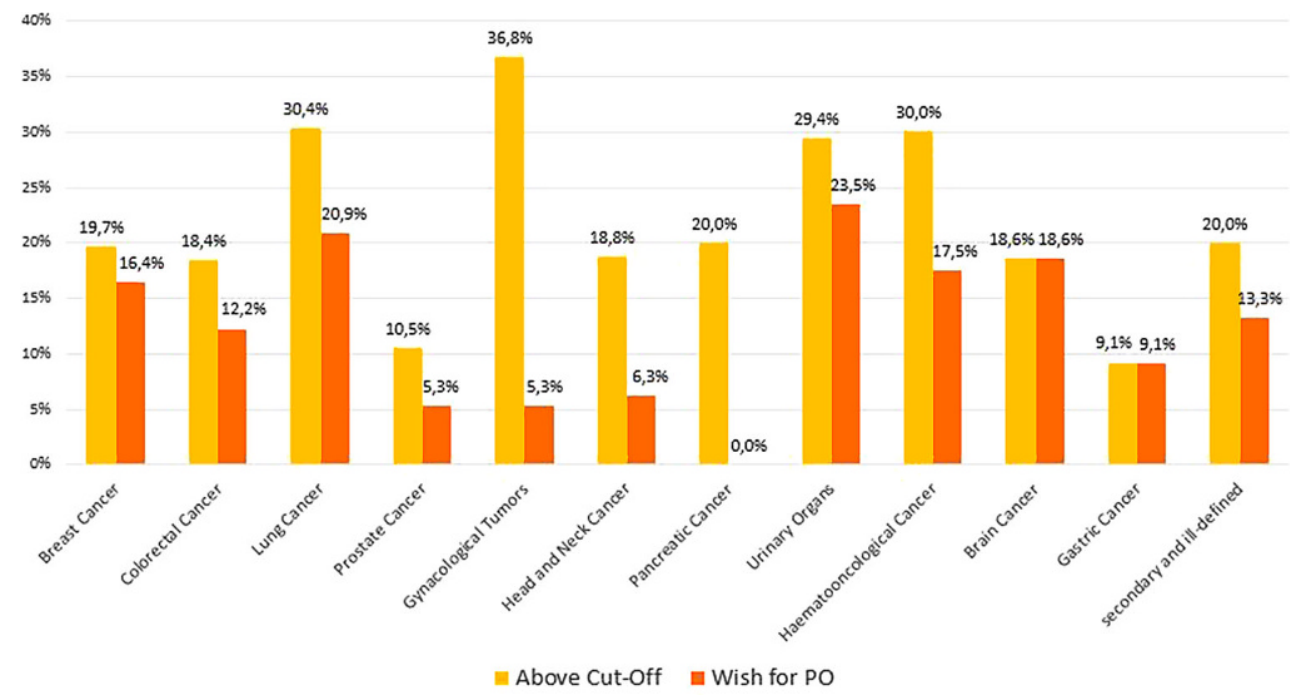

above the proposed cut-off and the number of patients who wished for PO amongst some cancer entities. While the HSI cut-off seemed to reflect the wish for PO well in patients with brain cancer, gastric cancer, and breast cancer, our results showed large differences in patients with gynecological tumors, pancreatic tumors, and head and neck cancer.

\section{Association of sociodemographic and clinical characteristics with the subjective need for psychological support}

The omnibus test showed that the logistic regression model was statistically significant $\left(\chi^{2}=209165, p<0.001\right)$ and explained $42.5 \%$ (Nagelkerke R2) of the variance. The model was able to correctly classify $90.5 \%$ of the cases, which indicates excellent adequacy.

All nine variables entered in the final model remained statistically significant. Highest odds ratios regarding 
Table 2 Multivariate logistic regression model: Influential factors on patients wish for psychooncological support

\begin{tabular}{|c|c|c|c|c|c|c|c|}
\hline & \multirow[t]{2}{*}{$\begin{array}{l}\text { Regression } \\
\text { coefficient B }\end{array}$} & \multirow[t]{2}{*}{ Wald } & \multirow[t]{2}{*}{ df } & \multirow[t]{2}{*}{ Sig } & \multirow[t]{2}{*}{$\begin{array}{l}\text { Adjusted } \\
\text { OR }\end{array}$} & \multicolumn{2}{|c|}{$\begin{array}{l}95 \% \text { confidence } \\
\text { interval for OR }\end{array}$} \\
\hline & & & & & & Lower & Upper \\
\hline Age & -0.02 & 4.59 & 1 & 0.032 & 0.98 & 0.96 & 0.99 \\
\hline $\begin{array}{l}\text { Level of education (dichotomized; high vs. low } \\
\text { education) }\end{array}$ & 0.73 & 6.95 & 1 & 0.008 & 2.07 & 1.21 & 3.55 \\
\hline Diagnosis & - & 8.80 & 3 & 0.032 & - & - & - \\
\hline Diagnosis: others ${ }^{a}$ & 0.00 & - & - & - & 1.0 & - & - \\
\hline Diagnosis: breast cancer & 0.65 & 3.79 & 1 & 0.051 & 1.91 & 0.99 & 3.66 \\
\hline Diagnosis: prostate cancer & -0.29 & 0.37 & 1 & 0.546 & 0.75 & 0.29 & 1.92 \\
\hline Diagnosis: lung cancer & 0.82 & 4.27 & 1 & 0.039 & 2.28 & 1.04 & 4.97 \\
\hline HSI Item 2: emotional well-being & - & 32.10 & 2 & $<0.001$ & - & - & - \\
\hline HSI Item 2: rather good ${ }^{\mathrm{a}}$ & 0.00 & - & - & - & 1.000 & - & - \\
\hline HSI Item 2: medium & 1.24 & 17.50 & 1 & $<0.001$ & 3.44 & 1.93 & 6.13 \\
\hline HSI Item 2: rather bad & 2.46 & 26.9 & 1 & $<0.001$ & 11.69 & 4.62 & 29.59 \\
\hline $\begin{array}{l}\text { HSI Item 3: Additional emotional burden unrelated } \\
\text { to disease }\end{array}$ & 0.69 & 5.00 & 1 & 0.025 & 1.99 & 1.09 & 3.65 \\
\hline HSI Item 4: Lack of social support & 2.24 & 28.57 & 1 & $<0.001$ & 9.39 & 4.13 & 21.34 \\
\hline $\begin{array}{l}\text { HSI Item 5: Burden on family through } \\
\text { hospital stay }\end{array}$ & 0.99 & 11.03 & 1 & 0.001 & 2.71 & 1.51 & 4.89 \\
\hline HSI Item 6: Inability to calm down & 1.03 & 7.77 & 1 & 0.005 & 2.80 & 1.36 & 5.78 \\
\hline
\end{tabular}

$O R$ odds ratio, $d f$ degree of freedom, $H S I$ hornheide screening instrument

${ }^{\mathrm{a}}$ category taken as reference group

the wish for PO were found in patients with low emotional well-being $(\mathrm{OR}=11.3)$ and lack of social support $(\mathrm{OR}=9.4)$. The significant predictors included lower age, higher level of education, lower emotional well-being, additional emotional burden unrelated to disease, less social support, burden on family through hospital stay, and the inability to relax. Regarding the type of cancer, there was an overall association of diagnosis with the dependent variable: patients with lung cancer had 2.3-times and patients with breast cancer 1.9-times higher odds to wish for PO compared to the combined remaining diagnoses (see Table 2).

We found no significant association of relationship status, parenthood, disease status (initial manifestation, metastases, secondary tumor, tumor recurrence), previous cancer-related treatments, and two HSI items (physical well-being, level of information about disease and treatment) on the dependent variable and therefore did not include these variables in the final model.

\section{Discussion}

PO aids patients in coping with various challenges that may occur during oncological radiotherapy. To facilitate optimal identification of distressed cancer patients, a stepwise approach was implemented at our Department. Firstly, all cancer patients are screened for distress using evaluated questionnaires. Secondly, all cancer patients who score above a predefined cut-off, articulate a need for PO, or are identified as distressed by the healthcare staff are contacted by a specialized psychologist and are then thirdly either treated at the unit or referred to appropriate external services. This approach is based on guidelines (i.e., [22]) as well as on our practical and clinical experiences at the department.

The aim of our study was to investigate how many cancer patients wished for PO during outpatient radiotherapy in this real-world setting. Our secondary goals were to investigate factors influencing the wish for $\mathrm{PO}$ and to describe the referral pathways for PO in clinical routine.

In the present cohort, $19.6 \%$ of the cancer patients reported values above the clinical cut-off and $13.1 \%$ of all cancer patients wished for PO. These incidence rates are in line with previous studies with a similar study design [5-7]. In controlled and experimental studies, reported incidence rates were significantly lower $[19,20]$. In these studies, the assessment periods were shorter and samples were smaller within predefined cancer subtypes. This underscores the importance of real-life data to evaluate the need for PO in cancer patients.

We observed eight variables, each independently influencing the wish for PO, namely lower emotional wellbeing, lack of social support, burden on family through hospital stay, the inability to calm down, and higher level of education. Furthermore, younger patients and patients with lung cancer or breast cancer had a significantly higher probability to wish for PO. Our observations suggest that 
self-reported psychosocial issues were significantly better predictors for the wish for PO than sociodemographic or clinical variables (i.e., sex, parenthood, previous oncological treatments, disease state), which is in line with previous research [28].

In the present cohort, patients with gynecological cancer, lung cancer, and hematological malignancies reported the highest levels of psychosocial distress. Previous research indicated that cancer patients from different entities differed in their need for PO: Singer et al. [29] reported that the wish for PO varied between 15 and $45 \%$ across different cancer entities in a large sample of mixed oncological inpatients. The largest proportion of patients wishing for PO in our study was found amongst patients with cancer of the urinary tract, lung cancer, and brain cancer. Acceptable accordance was observed between the level of psychosocial distress and the wish for PO in patients with breast cancer, brain cancer, or gastric cancer.

In contrast, discrepancy between psychosocial distress and acceptance of PO for other cancer types was profound: the largest discrepancies were found for patients with gynecological cancer, pancreatic cancer, head and neck cancer, and hematological cancer. This indicates that the HSI cutoff of $\geq 4$ may not be equally fit for all cancer entities. We therefore decided to add the Distress Thermometer to our screening procedure from now on, to gain more insight about suitable cut-off values for the different tumor entities.

Other reasons for this mismatch may be that patients with certain cancer types are more reluctant to accept PO: patients with head and neck cancer, for example, often suffer from a broad range of comorbidities [30], have a higher chance to suffer from depression [29], and are more likely to commit suicide than patients with other types of cancer [31]. Yet, in accordance with our findings, they are also less likely to ask for PO [29, 30]. In a recent study, Faller et al. [32] observed that while patients with gynecological cancer reported lower QoL than patients with breast cancer, there was no difference regarding their wish for PO. In our sample, patients with gynecological tumors most frequently reported values above the cut-off, yet the wish for PO was amongst the lowest of the whole sample. Regarding the subgroup of patients with gynecological cancer and pancreatic cancer, however, our results should be interpreted with great caution, since the samples were quite small. Nevertheless, our data suggest that further exploration of reasons for acceptance or rejection of PO (e.g., [33]) is warranted to improve clinical care for patients with all cancer entities.

In our understanding, especially in busy outpatient units, the combination of personal referral and short and quick screening procedures is a valid strategy to prevent the underdiagnoses of psychosocial distress. Interestingly, several patients wished for PO despite scoring below the proposed cut-off. This indicates that self-administered screening procedures may also encourage patients to seek PO as a preventive strategy or because of problems not related to their oncological disease. Also, cancer patients receive a feedback about their distress level, which may correct possible misjudgment of their own distress levels as not severe enough for PO.

Here, 204 cancer patients received at least one consultation. About $60 \%$ of the patients were seen more than once by a psychooncologist, with up to nine sessions per patient. Of the patients who were consulted only once, about $40 \%$ were referred to other healthcare services. This proposes that especially in treatment units with larger catchment areas, it is important to inform patients about treatment options closer to their home. Since many cancer patients face financial challenges, the integration of counseling by social workers at the treatment units is necessary.

For $40 \%$ of the cancer patients who received a psychooncological consultation, no screening data were available. This indicates two things: (a) screening can only be an additional tool to personal referral by healthcare professionals and (b) patients who do not return the screening instrument may also be distressed and may also profit from PO. No information on the reasons for non-participation in the screening procedure in our study was available. We have planned to further investigate reasons for non-participation at our center.

This topic is especially interesting to us since our data show that patients who had PO without prior screening information (i.e., referred by healthcare professionals) were consecutively referred to external services significantly more often than patients with screening results. A possible explanation could be that distressed patients who do not wish for PO at the unit may not know about the option to be referred to external services closer to home, and are therefore more reluctant to participate in the screening procedure. Nevertheless, in our experience, many of those patients still benefited from PO. The dropout rates in the paper and pencil assessment therefore hinder the optimal treatment and referral. The implementation of routine electronic screening procedures could help to minimize this effect and therefore help to better identify distressed patients.

We observed that patients are more likely to complete screening questionnaires if they experience active incorporation of the questionnaires' results into their individual treatment plan. We experienced that including the staff at the radiation units in the screening procedure (i.e., handing out the questionnaires) aided in implementing PO in the patients' clinical routine. This may facilitate de-stigmatization. Since cancer patients are regularly seen by the same staff during radiotherapy, they can be encouraged to accept PO help if necessary. Furthermore, routine screening might help patients to accept PO by (a) pointing out that such 
services exist and (b) helping patients to identify specific problems by asking specific questions.

\section{Limitations}

One major limitation of our study was the participation rate of approximately $55 \%$. While this is comparable to other retrospective analyses of paper and pencil data collected in clinical routine $[34,35]$, it still hinders the generalizability of our observations. Moreover, we do not know the reasons for non-participation or whether all patients received a screening questionnaire. One influence on the noncompletion rate may be the mode of assessment: Gamper et al. [34] found higher non-completion rates and poorer adherence rates for paper and pencil routine assessments compared to electronic assessments. Electronic assessments enable the psychologists to approach the patients more quickly, since screening results are available immediately after completion. Previous studies indicated that the implementation of electronic assessments during outpatient radiotherapy is feasible, and the majority of patients are highly willing to complete electronic assessments $[5,7,36]$.

Also, screening was only conducted once, at the beginning of radiotherapy. While side effects mostly do not occur at the beginning of the treatment, physical well-being is likely to decrease during the course of the treatment. Additional screening during and/or at the end of the treatment phase may result in higher incidence numbers of psychosocial distress and a higher number of patients wishing for PO. Based on the comparably high number of patients who were additionally referred to PO during the study period, our incidence numbers may even underrepresent the true number of patients who would require PO.

Finally, the retrospective study design prevents us from evaluation of the proportion of patients who might had been referred to PO even if no screening would have been performed. However, previous studies observed that oncologists tend to underestimate the patients' distress levels and their need for PO $[4,17]$.

\section{Conclusion}

PO is an important supportive therapy during radiotherapy in cancer patients, especially for emotionally distressed and socially deprived patients. To facilitate the early detection and referral of distressed patients, screening should be integrated into routine clinical care. Routine distress screening may be helpful to further de-stigmatize PO by presenting it as normal part of clinical routine. However, paper and pencil-based assessment procedures impede the immediate use of the test results and may lead to lower response rates. The electronic collection of screening questionnaires might facilitate referral and improve participation rates in the screening procedure.

Acknowledgements We want to thank Jörg Kemmler for statistical advice and Ryan Lundstrom for language editing and proof reading.

Funding Open access funding provided by University of Innsbruck and Medical University of Innsbruck.

\section{Compliance with ethical guidelines}

Conflict of interest D. Riedl, R. Gastl, E. Gamper, C.R. Arnold, D. Dejaco, F. Schoellmann, and G. Rumpold declare that they have no competing interests.

Ethical standards All procedures performed in studies involving human participants were in accordance with the ethical standards of the institutional and/or national research committee and with the 1964 Helsinki declaration and its later amendments or comparable ethical standards.

Open Access This article is distributed under the terms of the Creative Commons Attribution 4.0 International License (http:// creativecommons.org/licenses/by/4.0/), which permits unrestricted use, distribution, and reproduction in any medium, provided you give appropriate credit to the original author(s) and the source, provide a link to the Creative Commons license, and indicate if changes were made.

\section{References}

1. Fitzmaurice C, Allen C, Barber RM et al (2017) Global, regional, and national cancer incidence, mortality, years of life lost, years lived with disability, and disability-adjusted life-years for 32 cancer groups, 1990 to 2015: a systematic analysis for the Global Burden of Disease Study. JAMA Oncol 3(4):524-548. https://doi.org/10. 1001/jamaoncol.2016.5688

2. Aaronson NK, Mattioli V, Minton O, Weis J, Johansen C, Dalton SO, Verdonck-de Leeuw IM, Stein KD, Alfano CM, Mehnert A, de Boer A, van de Poll-Franse LV (2014) Beyond treatment-psychosocial and behavioural issues in cancer survivorship research and practice. EJC Suppl 12(1):54-64

3. Korner P, Ehrmann K, Hartmannsgruber J, Metz M, Steigerwald S, Flentje M, van Oorschot B (2017) Patient-reported symptoms during radiotherapy: clinically relevant symptom burden in patients treated with palliative and curative intent. Strahlenther Onkol 193(7):570-577. https://doi.org/10.1007/s00066-017-1146-5

4. Sollner W, DeVries A, Steixner E, Lukas P, Sprinzl G, Rumpold G, Maislinger S (2001) How successful are oncologists in identifying patient distress, perceived social support, and need for psychosocial counselling? Br J Cancer 84(2):179-185. https://doi.org/10.1054/ bjoc. 2000.1545

5. Dinkel A, Berg P, Pirker C, Geinitz H, Sehlen S, Emrich M, Marten-Mittag B, Henrich G, Book K, Herschbach P (2010) Routine psychosocial distress screening in radiotherapy: implementation and evaluation of a computerised procedure. Br J Cancer 103(10):1489-1495. https://doi.org/10.1038/sj.bjc.6605930

6. Kirchheiner K, Czajka A, Ponocny-Seliger E, Lutgendorf-Caucig C, Schmid MP, Komarek E, Potter R, Dorr W (2013) Physical and psychosocial support requirements of 1,500 patients starting radiotherapy. Strahlenther Onkol 189(5):424-429. https://doi.org/ 10.1007/s00066-013-0329-y

7. Mackenzie LJ, Carey ML, Sanson-Fisher RW, D'Este CA (2013) Psychological distress in cancer patients undergoing radiation therapy treatment. Support Care Cancer 21(4):1043-1051. https://doi. org/10.1007/s00520-012-1624-3 
8. Yee MK, Sereika SM, Bender CM, Brufsky AM, Connolly MC, Rosenzweig MQ (2017) Symptom incidence, distress, cancerrelated distress, and adherence to chemotherapy among African American women with breast cancer. Cancer 123(11):2061-2069. https://doi.org/10.1002/cncr.30575

9. Kennard BD, Stewart SM, Olvera R, Bawdon RE, O'Hailin A, Lewis CP, Winick NJ (2004) Nonadherence in adolescent oncology patients: preliminary data on psychological risk factors and relationships to outcome. J Clin Psychol Med Settings 11(1):30-39. https://doi.org/10.1023/B:JOCS.0000016267.21912.74

10. Von Essen L, Larsson G, Oberg K, Sjödén PO (2002) 'Satisfaction with care': associations with health-related quality of life and psychosocial function among Swedish patients with endocrine gastrointestinal tumours. Eur J Cancer Care (Engl) 11(2):91-99

11. Skarstein J, Aass N, Fossa SD, Skovlund E, Dahl AA (2000) Anxiety and depression in cancer patients: relation between the hospital anxiety and depression scale and the European Organization for Research and Treatment of Cancer Core Quality of Life Questionnaire. J Psychosom Res 49(1):27-34

12. Faller H, Schuler M, Richard M, Heckl U, Weis J, Kuffner R (2013) Effects of psycho-oncologic interventions on emotional distress and quality of life in adult patients with cancer: systematic review and meta-analysis. J Clin Oncol 31(6):782-793. https://doi. org/10.1200/jco.2011.40.8922

13. Hart SL, Hoyt MA, Diefenbach M, Anderson DR, Kilbourn KM, Craft LL, Steel JL, Cuijpers P, Mohr DC, Berendsen M, Spring B, Stanton AL (2012) Meta-analysis of efficacy of interventions for elevated depressive symptoms in adults diagnosed with cancer. J Natl Cancer Inst 104(13):990-1004. https://doi.org/10.1093/jnci/djs256

14. Mitchell AJ (2013) Screening for cancer-related distress: when is implementation successful and when is it unsuccessful? Acta Oncol 52(2):216-224. https://doi.org/10.3109/0284186x.2012.745949

15. Carlson LE, Angen M, Cullum J, Goodey E, Koopmans J, Lamont L, MacRae JH, Martin M, Pelletier G, Robinson J, Simpson JS, Speca M, Tillotson L, Bultz BD (2004) High levels of untreated distress and fatigue in cancer patients. Br J Cancer 90(12):2297-2304. https://doi.org/10.1038/sj.bjc.6601887

16. Verdonck-de Leeuw IM, de Bree R, Keizer AL, Houffelaar T, Cuijpers P, van der Linden MH, Leemans CR (2009) Computerized prospective screening for high levels of emotional distress in head and neck cancer patients and referral rate to psychosocial care. Oral Oncol 45(10):e129-133. https://doi.org/10.1016/j.oraloncology. 2009.01.012

17. Bauwens S, Baillon C, Distelmans W, Theuns P (2014) Systematic screening for distress in oncology practice using the Distress Barometer: the impact on referrals to psychosocial care. Psychooncology 23(7):804-811. https://doi.org/10.1002/pon.3484

18. Loth FL, Meraner V, Holzner B, Singer S, Virgolini I, Gamper EM (2018) Following patient pathways to psycho-oncological care: identification of treatment needs by clinical staff and electronic screening. Psychooncology. https://doi.org/10.1002/pon.4675

19. de Vries A, Sollner W, Steixner E, Auer V, Schiessling G, Stzankay A, Iglseder W, Lukas P (1998) Subjective psychological stress and need for psychosocial support in cancer patients during radiotherapy treatment. Strahlenther Onkol 174(8):408-414

20. Faller H, Olshausen B, Flentje M (2003) Emotional distress and needs for psychosocial support among breast cancer patients at start of radiotherapy. Psychother Psychosom Med Psychol 53(5):229-235. https://doi.org/10.1055/s-2003-38864

21. NCCN (2003) Distress management. Clinical practice guidelines. J Natl Compr Canc Netw 1(3):344-374

22. AWMF, DKG, DKH (2014) Psychooncological diagnostics, support and treatment of adult cancer patients-German Oncological Guidelines. Leitlinienprogramm Onkologie der Arbeitsgemeinschaft der Wissenschaftlichen Medizinischen Fachgesellschaften e. V. (AWMF), Deutschen Krebsgesellschaft e. V. (DKG) und
Deutschen Krebshilfe e. V. (DKH). http://leitlinienprogrammonkologie.de/Leitlinien.7.0.html. Accessed 8 May 2017

23. Feldstain A, Tomei C, Belanger M, Lebel S (2014) Screening for distress in patients with cancer: methodologic considerations. Curr Oncol 21(2):e330-333. https://doi.org/10.3747/co.21.1794

24. Clover KA, Mitchell AJ, Britton B, Carter G (2015) Why do oncology outpatients who report emotional distress decline help? Psychooncology 24(7):812-818. https://doi.org/10.1002/pon.3729

25. Waller A, Williams A, Groff SL, Bultz BD, Carlson LE (2013) Screening for distress, the sixth vital sign: examining self-referral in people with cancer over a one-year period. Psychooncology 22(2):388-395. https://doi.org/10.1002/pon.2102

26. Carolan CM, Smith A, Davies GR, Forbat L (2017) Seeking, accepting and declining help for emotional distress in cancer: a systematic review and thematic synthesis of qualitative evidence. Eur J Cancer Care (Engl). https://doi.org/10.1111/ecc.12720

27. Kam LY, Knott VE, Wilson C, Chambers SK (2012) Using the theory of planned behavior to understand health professionals' attitudes and intentions to refer cancer patients for psychosocial support. Psychooncology 21(3):316-323. https://doi.org/10.1002/pon. 1897

28. Admiraal JM, van Nuenen FM, Burgerhof JG, Reyners AK, Hoekstra-Weebers JE (2016) Cancer patients' referral wish: effects of distress, problems, socio-demographic and illness-related variables and social support sufficiency. Psychooncology 25(11):1363-1370. https://doi.org/10.1002/pon.4067

29. Singer S, Bringmann H, Hauss J, Kortmann RD, Kohler U, Krauss O, Schwarz R (2007) Prevalence of concomitant psychiatric disorders and the desire for psychosocial help in patients with malignant tumors in an acute hospital. Dtsch Med Wochenschr 132(40):2071-2076. https://doi.org/10.1055/s-2007-985643

30. Moschen R, Riedl D (2017) Psychooncological treatment of patients with head and neck cancer. Laryngorhinootologie. https://doi. org/10.1055/s-0037-1600929

31. Oberaigner W, Sperner-Unterweger B, Fiegl M, Geiger-Gritsch S, Haring C (2014) Increased suicide risk in cancer patients in Tyrol/Austria. Gen Hosp Psychiatry 36(5):483-487. https://doi.org/ 10.1016/j.genhosppsych.2014.05.017

32. Faller H, Brahler E, Harter M, Keller M, Schulz H, Wegscheider K, Weis J, Boehncke A, Reuter K, Richard M, Sehner S, Koch U, Mehnert A (2017) Unmet needs for information and psychosocial support in relation to quality of life and emotional distress: a comparison between gynecological and breast cancer patients. Patient Educ Couns. https://doi.org/10.1016/j.pec.2017.05.031

33. Zwahlen D, Tondorf T, Rothschild S, Koller MT, Rochlitz C, Kiss A (2017) Understanding why cancer patients accept or turn down psycho-oncological support: a prospective observational study including patients' and clinicians' perspectives on communication about distress. BMC Cancer 17(1):385. https://doi.org/10.1186/s12885017-3362-x

34. Gamper EM, Nerich V, Sztankay M, Martini C, Giesinger JM, Scarpa L, Buxbaum S, Jeller M, Holzner B, Virgolini I (2017) Evaluation of noncompletion bias and long-term adherence in a 10year patient-reported outcome monitoring program in clinical routine. Value Health 20(4):610-617. https://doi.org/10.1016/j.jval. 2017.01.009

35. Dudgeon D, King S, Howell D, Green E, Gilbert J, Hughes E, Lalonde B, Angus H, Sawka C (2012) Cancer Care Ontario's experience with implementation of routine physical and psychological symptom distress screening. Psychooncology 21(4):357-364. https://doi.org/10.1002/pon.1918

36. Kirchheiner K, Czajka A, Ponocny-Seliger E, Komarek E, Hohenberg G, Potter R, Dorr W (2013) Validation and practical implementation of a multidisciplinary cancer distress screening questionnaire. Strahlenther Onkol 189(7):573-578. https://doi.org/10.1007/ s00066-013-0348-8 